The 2003 Licensing Act

\section{The 2003 Licensing Act: an act of stupidity?}

S Goodacre
As the 2003 Licensing Act comes into effect, what will the impact of the extending drinking hours be on UK emergency departments?

$\mathrm{T}$ he 2003 Licensing Act will be coming into effect shortly in England and Wales. This removes restrictions on the sale of alcohol from bars and pubs, extending drinking time beyond $11 \mathrm{pm}$. The Government hopes that this will lead to the English taking a more relaxed approach to drinking, and reduce the incidence of drunkenness, assaults, and anti-social behaviour often seen after $1 \mathrm{lpm}$ closing. Senior police officers and judges are sceptical and have warned of increasing alcoholrelated crime and violence.

What are the implications for emergency departments? Will people sip wine at late-night cafes while the emergency departments lie empty, or will an orgy of drunken violence engulf the country, with its' victims overwhelming hospitals? Data from Scotland suggest that there will be no immediate dramatic impact from altering licensing hours, ${ }^{1}$ but underlying trends are more concerning. Alcohol is currently responsible for a substantial number of emergency department attendances and hospital admissions, particularly at night. ${ }^{23}$ Alcohol use has been rising in the United Kingdom and with it the burden of alcohol-related ill health. ${ }^{4}$ Over the same time period emergency department attendances, admissions, and waiting times have also increased. ${ }^{5}$ Waiting times already tend to be longer at night, with many people leaving before they receive medical attention. $^{6}$ Even if extending licensing hours only changes the timing of alcohol-related incidents it will still place more pressure on emergency departments when they are already struggling to meet demand.

Liberalising licensing laws is likely to do more than just alter the timing of alcohol-related incidents. Availability of alcohol is associated with increased use, which is in turn related to increased alcohol related injury and illness. ${ }^{7}$ At a time when alcohol-related deaths have risen by $20 \%$ in the last 5 years, ${ }^{4}$ it seems perverse, to say the least, to be choosing to increase availability of alcohol.

The likely outcome of the Licensing Act is, therefore, neither a dramatic improvement nor worsening, but continuing progression of an already depressing situation. So what can emergency clinicians do about this? The Licensing Act contains new powers for the police and local authorities to close licensed premises that are associated with alcohol-related problems. Emergency department data has previously been used to identify problem locations and target police resources. ${ }^{8}$ These data could be used to inform licensing decisions. Emergency clinicians are respected and have potentially powerful local voices. They should be prepared to liaise with local authorities to ensure that the impact upon emergency services is taken into account.

Alcohol is a huge cause of illness and injury in the United Kingdom and is a major threat to our ability to sustain high-quality emergency care. To increase availability of alcohol at a time when the problem is escalating, as the Licensing Act does, appears to lack common sense. Unless the new powers to close problem premises are used effectively the Act will just exacerbate an already serious problem. Meanwhile, emergency clinicians will have to carry on clearing up the mess.

Emerg Med J 2005;22:682.

doi: 10.1136/emj.2005.030049

Correspondence to: Steve Goodacre, Medical Care Research Unit, University of Sheffield, Sheffield, UK; S.Goodacre@sheffield.ac.uk

Accepted for publication 24 August 2005

\section{REFERENCE}

1 Graham CA, McLeod LS, Steedman DJ. Restricting extensions to permitted licensing hours does not influence the numbers of alcohol or assault related attendances at an inner city accident and emergency department. J Accid Emerg Med 1998; 15:23-5.

2 Simpson T, Murphy N, Peck DF. Saliva alcohol concentrations in accident and emergency attendances. Emerg Med J 2001;18:250-4

3 Pirmohamed M, Brown C, Owen L, et al. The burden of alcohol misuse on an inner-city general hospital. Q J Med 2000;93:291-5.

4 Office for National Statistics (ONS). Alcoholrelated death rates in England and Wales, 2001 to 2003. http://www. statistics.gov.uk/ STATBASE/ssdataset.asp?vlnk = 8905 (accessed 19/08/05).

5 Locker T, Mason S, Wardrope J, et al. Targets and moving goalposts: changes in waiting times in a UK emergency department. Emerg Med J 2005;22:710-5

6 Goodacre S, Webster A. Who waits longest in the emergency department and who leaves without being seen? Emerg Med J 2005;22:93-96.

7 Rush BR, Glicksman L, Brook R. Alcohol availability, alcohol consumption and alcoholrelated damage. I. The distribution of consumption model. J Stud Alcohol 1986;47:1-10.

8 Warburton AL, Shepherd JP. Development, utilisation, and importance of accident and emergency department derived assault data in violence management. Emerg Med J 2004;21:473-7. 